\title{
Effect of omega-3 fatty acids supplementation on cardio-metabolic and oxidative stress parameters in patients with chronic kidney disease: a systematic review and meta-analysis
}

Siavash Fazelian', Fatemeh Moradi², Shahram Agah³ ${ }^{3}$ Akramsadat Hoseini ${ }^{4}$, Hafez Heydari ${ }^{5}$, Mojgan Morvaridzadeh ${ }^{6}$, Amirhosein Omidi ${ }^{6}$, Ana Beatriz Pizarro ${ }^{7}$, Atie Ghafouri ${ }^{*^{*}}$ and Javad Heshmati ${ }^{6^{*}}$ (D)

\begin{abstract}
Background: Omega-3 fatty acids (FAs) have been suggested as a beneficial supplement in chronic kidney disease (CKD) patients, but the results of randomized clinical trials (RCTs) are controversial. We conducted a systematic review and meta-analysis to evaluate all the RCTs about the impact of omega-3 FAs supplementation on cardiometabolic outcomes and oxidative stress parameters in patients with CKD.

Methods: We performed a systematic database search in PubMed/MEDLINE, EMBASE, Scopus, Web of Science, and Cochrane Central, up to May 2020. We included all placebo-controlled randomized trials that assessed the effect of omega-3 FAs supplementation on any cardiometabolic outcomes: blood pressure, total cholesterol (TC), low-density lipoprotein (LDL) and high-density lipoprotein (HDL) or triglycerides (TG) and oxidative stress parameters. Data were pooled using DerSimonian-Laird's random-effects model.
\end{abstract}

Results: Finally, thirteen articles met the inclusion criteria for this review omega-3 FAs supplementation significantly decrease TC (SMD: $\left.-0.26 ; 95 \% \mathrm{Cl}:-0.51,-0.02 ; \mathrm{I}^{2}=52.7 \%\right)$, TG (SMD: $\left.-0.22 ; 95 \% \mathrm{Cl}:-0.43,-0.02 ; \mathrm{I}^{2}=36.0 \%\right)$ and Malondialdehyde (MDA) levels (SMD: $\left.-0.91 ; 95 \% \mathrm{Cl}:-1.29,-0.54 ; \mathrm{I}^{2}=00.0 \%\right)$ and also significantly increase superoxide dismutase (SOD) (SMD: 0.58; 95\% Cl: 0.27, 0.90; $\left.1^{2}=00.0 \%\right)$ and Glutathione peroxidase (GPX) (SMD: 0.50; $95 \%$ Cl: $0.14,0.86 ; I^{2}=00.0 \%$ ) activities. However our results show that omega-3 FAs supplementation have no significant effects on $\mathrm{HDL}, \mathrm{LDL}$ and blood pressure.

Conclusion

This systematic review and meta-analysis supports current evidence for the clinical benefit of omega-3 FAs intake to (Continued on next page)

\footnotetext{
* Correspondence: atie.ghafouri@gmail.com; javad.heshmati@gmail.com

${ }^{8}$ Department of Nutrition, School of Public Health, Iran University of Medical Sciences, Tehran, Iran

${ }^{6}$ Department of Nutritional Science, School of Nutritional Science and Food Technology, Kermanshah University of Medical Sciences, Farabi Hospital,

Faculty of Nutrition Sciences and Food Technology, Postal Code: 6715847141, Isar Square, Kermanshah, Iran

Full list of author information is available at the end of the article
}

(c) The Author(s). 2021 Open Access This article is licensed under a Creative Commons Attribution 4.0 International License, which permits use, sharing, adaptation, distribution and reproduction in any medium or format, as long as you give appropriate credit to the original author(s) and the source, provide a link to the Creative Commons licence, and indicate if changes were made. The images or other third party material in this article are included in the article's Creative Commons licence, unless indicated otherwise in a credit line to the material. If material is not included in the article's Creative Commons licence and your intended use is not permitted by statutory regulation or exceeds the permitted use, you will need to obtain permission directly from the copyright holder. To view a copy of this licence, visit http://creativecommons.org/licenses/by/4.0/ The Creative Commons Public Domain Dedication waiver (http://creativecommons.org/publicdomain/zero/1.0/) applies to the data made available in this article, unless otherwise stated in a credit line to the data. 
(Continued from previous page)

improve cardiometabolic parameters in CKD patients. However, well-designed RCTs still needed to provide a conclusive picture in this field.

Keywords: Cardio-metabolic outcomes, CKD, Omega-3 FAs, Oxidative stress, Blood lipids

\section{Highlights}

- Chronic kidney disease (CKD) is the progressive loss of renal function that recognized as a global public health problem

- Omega-3 fatty acids (FAs) have beneficial supplement in chronic kidney disease (CKD) patientssss

- Omega-3 FAs intake significantly improves lipid profile and increases antioxidant defense enzymes in CKD patients.

\section{Background}

Long-chain Omega-3 fatty acids such as, docosahexaenoic acid (DHA) and eicosapentaenoic acid (EPA), are polyunsaturated fatty acids that mostly intake from seafood $[1,2]$. Omega-3 fatty acids (FAs) are widely used to manage disease and complications [3]. Omega-3 FAs because of antioxidant properties can protect the cardiovascular system from oxidative stress and thrombotic complications [4].

Patients with chronic kidney diseases (CKD) who are maintained with dialysis or nephropathy have a risk of coronary heart disease, myocardial infarction, and atherosclerosis [5, 6]. Cardiometabolic factors such as hypertension, dyslipidemia, hyperglycemia, and obesity are determinant risk factors in the general population [7, 8]. Cardiometabolic risk factors impose a great burden on health and insurance systems all over the world $[9,10]$ and they are even more harmful in people with underlying diseases such as CKD [11-13]. Elevated levels of low-density lipoprotein (LDL), accumulate remnant lipoproteins as well as oxidized LDL (ox-LDL) and generate atherosclerosis [14]. Patients, undergoing hemodialysis, are at higher risk due to metabolic changes, increased lipid profile can result in unpleasant disorders that must be prevented [15]. However, lipid profile especially TC levels considered as nutritional parameters [16], which have been demonstrated to be strictly related to cardiometabolic risks in CKD patients [17].

Patients with end-stage renal disease (ESRD) do not receive enough omega-3 fatty acids due to limited consumption of rich food of omega-3 fatty acids, such as nuts and fishes [18]. Some of the RCTs indicated the administration of $\mathrm{n}-3$ fatty acids has a beneficial effect on serum lipid profile, but maybe depending on the selected dose [19]. Recent randomized controlled trials (RCTs) show omega-3 supplements (EPA and DHA) usually have opposite effects versus placebo [18, 20].

Previous clinical trials have examined the effect of omega-3 supplements on cardiometabolic factors that have been performed in patients with CKD, but no meta-analysis and systematic review reported the overall impact of n-3 PUFA clinical trials. Thus, our study aimed to evaluate the overall effects of oral omega-3 supplementation on serum lipid profile, hypertension and antioxidant markers in CKD patients.

\section{Methods}

\section{Search strategy}

This meta-analysis was performed according to the PRIS MA guidelines [21]. Electronic databases, including PubMed/MEDLINE, EMBASE, Scopus, ISI Web of Science, and Cochrane Central, were systematically searched up to May 2020. The search strategy was conducted without any language or time restriction. Mesh terms were used to PubMed and topic heading titles were used for other databases search. The systematic search was completed using the following terms: Fish Oil OR Fatty Acids, Omega-3 OR Docosahexaenoic Acids OR "DHA" OR Eicosapentaenoic Acid OR "EPA" OR Timnodonic Acid AND Dialysis OR Hemodialysis OR Peritoneal dialysis OR Kidney disease OR Chronic kidney disease OR End stage renal disease OR Chronic renal failure AND Randomized controlled trial OR controlled clinical trial OR randomized controlled trials. Complete search terms and syntaxes are presented in Additional file 1.

\section{Study selection \& quality appraisal}

The titles and abstracts of the studies were screened by two independent investigators (S.F and F.M), then the full text of the related articles was checked, and any disagreements were resolved by consensus. All human clinical trials that reported the effect of omega-3 supplementation on cardiometabolic factors in chronic kidney patients were included in the current meta-analysis. Experimental studies, trials that used a combination of omega- 3 and other interventions and studies that used olive oil or medium-chain triglyceride (MCT) as a placebo, were excluded. The primary outcomes of this review were cardiometabolic factors such as blood lipids (TC, TG, LDL and HDL), and systolic or diastolic blood 
pressure. The secondary outcomes were oxidative stress parameters (TAC, MDA, SOD and Gpx activity). We evaluated the methodological quality of each included trial using criteria from the Cochrane Collaboration guidelines [22].

\section{Data extraction and data analysis}

The review of primary studies was performed by one author (S.F) and then the data were double-checked by a second one (F.M) and any discrepancies were discussed by the other author (J.H), we extracted general characteristics of the study include of first author's name, year of publication, country, subjects, sample size, mean age, gender, dose and type of supplemented omega- 3 and main outcomes that has been indicated in Table 1. The mean and standard deviation of the primary outcomes associated with cardiometabolic were extracted from related articles for continuous and binary data we calculated the standardized mean difference (SMD). Standard Errors (SE), confidence interval, interquartile range $(I Q R)$, and minimum-maximum value of each cardiometabolic marker in omega-3 and placebo group were converted to Standard Deviations (SD).

All statistical analysis was performed with a random effect model based on the Inverse-Variance method using STATA software version 13 (STATA Corp, College Station, Texas). We assessed the heterogeneity of studies using heterogeneity chi-squared tests with a $P$-value of less than 0.1 and $\mathrm{I}^{2}$ statistic more than $50 \%$ considered as significant heterogeneity [22]. Subgroup analysis based on duration and dose of omega-3 FAs supplementation was conducted. The funnel plot, Begg and Egger test were used to evaluate the publication bias of included trials [36]. Sensitivity analysis was performed to assess the extent to which inferences might depend on an individual trial.

\section{Results \\ Search results}

The study identification and study selection process is presented in the PRISMA flow diagram in Fig. 1. Initial database search yielded an aggregate of 1405 potentially relevant records. After reading the title and abstract of duplicate removed records, 36 studies remained for the comprehensive full-text evaluations. Of these 36 articles, 23 more studies were excluded for various reasons. Finally, 13 articles [23-35] met the inclusion criteria for this review.

\section{Study characteristics}

The main characteristics of the included articles are presented in Table 1. All the included studies were published between 1994 and 2017. The included trials originated from the Iran $(n=7)$, the United States $(n=$
1), Egypt $(n=1)$, Algeria $(n=1)$, Japan $(n=1)$, Sweden $(n=1)$, and Greece $(n=1)$. The total number of participants in all included trials was 708. Ten studies evaluated the effect of omega-3 FAs on hemodialysis patients [23, 24, 27-31, 33-35], two IgA nephropathy patients [26, 32] and one in chronic renal failure patients [25]. The duration of omega-3 supplementation in studies ranged from 8 to 192 weeks. The mean age of participants in included studies ranged from 14.1 to 64 years old. Among the 13 included studies, one used EPA-only supplements [23], and the other 12 trials involved supplementation of EPA/DHA combinations. Omega-3 FAs dosage ranged from 1000 to $6000 \mathrm{mg} /$ day in trials.

\section{Risk of bias assessment}

The risk of bias evaluation of included studies is shown in Additional file 2. Overall, seven trials reported on random sequence generation [26-28, 30, 31, 33, 34], seven reported precise and correct allocation concealment [23, $24,27,30,31,33,34]$. Five trials were evaluated as having a high risk of performance bias [23, 26, 28, 29, 35] and only two studies have evaluated as have a low detection bias $[25,31]$. Three studies were considered to have attrition bias $[25,30,32]$ and the risk of selective reporting was high in two trials $[23,32]$.

\section{Blood pressure}

Two included studies evaluated the effects of omega-3 FAs supplementation on blood pressure in CKD patients. The results of meta-analysis show that omega-3 FAs supplementation have no effect on SBP (SMD: -0.74; 95\% CI: - 1.56, 0.07; $\mathrm{I}^{2}=74.4 \%$ ) (Fig. 2a) and DBP (SMD: -0.33; 95\% CI: - 1.36, 0.70; $\mathrm{I}^{2}=84.3 \%$ ) (Fig. 2b).

\section{Blood lipids}

Meta-analysis of 11 included trials show that omega-3 FAs supplementation significantly reduce TC levels in CKD patients (SMD: -0.26 ; 95\% CI: $-0.51,-0.02$; $\mathrm{I}^{2}=$ 52.7\%) (Fig. 3a). Subgroup analysis based on duration did not show any significant changes (Table. 2), but subgroup analysis based on the dose of omega-3 FAs supplementation shows that omega-3 FAs supplementation is less or equal to $2000 \mathrm{mg} /$ day significantly decrease TC levels (Table. 2). Meta-analysis of 12 included studies demonstrated that omega-3 FAs supplementation significantly reduce TG levels in CKD patients (SMD: -0.22; 95\% CI: $-0.43,-0.02$; $\mathrm{I}^{2}=36.0 \%$ ) (Fig. 3b). stratification of results according to the duration of omega- 3 FAs supplementation indicates that TG decreased significantly in more than 10 weeks of omega-3 FAs supplementation (SMD: -0.36 ; 95\% CI: $-0.63,-0.10$; $\mathrm{I}^{2}=38.3 \%$ ) (Table. 2). According to omega-3 FAs doses, subgroup analysis did not show any significant changes (Table. 2). Meta-analysis on ten studies that evaluated 
Table 1 Main characteristics of included studies

\begin{tabular}{|c|c|c|c|c|c|c|c|c|c|c|c|c|}
\hline \multirow[t]{2}{*}{ Study (year) } & \multirow[t]{2}{*}{ Country } & \multirow[t]{2}{*}{ Subjects } & \multirow[t]{2}{*}{$\begin{array}{l}\text { Sample } \\
\text { size }\end{array}$} & \multicolumn{4}{|c|}{$\begin{array}{l}\mathrm{N}-3 \text { fatty acids Dosage } \\
\text { (per day) }\end{array}$} & \multirow[t]{2}{*}{$\begin{array}{l}\text { Duration } \\
\text { (week) }\end{array}$} & \multirow[t]{2}{*}{$\begin{array}{l}\text { Gender } \\
\text { (M/F) }\end{array}$} & \multicolumn{2}{|l|}{ Age } & \multirow[t]{2}{*}{$\begin{array}{l}\text { Main } \\
\text { outcome }\end{array}$} \\
\hline & & & & $\begin{array}{l}\mathrm{N}-3 \\
\text { Dose } \\
\text { (mg) }\end{array}$ & $\begin{array}{l}\text { EPA } \\
\text { (mg) }\end{array}$ & $\begin{array}{l}\text { DHA } \\
(\mathrm{mg})\end{array}$ & $\begin{array}{l}\text { ALA } \\
(\mathrm{mg})\end{array}$ & & & $\begin{array}{l}\text { Placebo } \\
\text { Mean } \pm \text { SD }\end{array}$ & $\begin{array}{l}\text { Intervention } \\
\text { Mean } \pm \text { SD }\end{array}$ & \\
\hline $\begin{array}{l}\text { Ando } \\
\text { et al [23] } \\
(1999)\end{array}$ & Japan & $\mathrm{HD}^{\mathrm{a}}$ & 38 & 1800 & 1638 & - & - & 12 & $33 / 5$ & $51 \pm 13$ & $54 \pm 11$ & $\begin{array}{l}\downarrow T^{c}, \downarrow T^{d}{ }^{d}, \\
\leftrightarrow H D L^{e}\end{array}$ \\
\hline $\begin{array}{l}\text { Ateya } \\
\text { et al [24] } \\
(2017)\end{array}$ & Egypt & $\mathrm{HD}$ & 49 & 1000 & 500 & 250 & - & 16 & $27 / 22$ & $14.6 \pm 2.7$ & $14.7 \pm 2.7$ & $\begin{array}{l}\leftrightarrow T C, \downarrow T G, \\
\leftrightarrow H D L, \\
\leftrightarrow L^{\prime} L^{\prime} \\
\leftrightarrow M D A^{\prime} g \\
, \uparrow G P x{ }^{h}, \uparrow S O D{ }^{i}\end{array}$ \\
\hline $\begin{array}{l}\text { Bouzidi } \\
\text { et al [25] } \\
(2010)\end{array}$ & Algeria & $\mathrm{CRF}^{\mathrm{b}}$ & 40 & 2100 & 693 & 252 & - & 12 & $22 / 18$ & $61 \pm 14$ & $61 \pm 14$ & $\begin{array}{l}\downarrow T G, \\
\uparrow G P x, \\
\uparrow S O D, \\
\leftrightarrow H D L, \leftrightarrow L D L, \\
\leftrightarrow T C\end{array}$ \\
\hline $\begin{array}{l}\text { Alexopoulos } \\
\text { et al [26] } \\
\text { (2004) }\end{array}$ & Greece & $\begin{array}{l}\text { IgA } \\
\text { Nephropathy }\end{array}$ & 28 & 3000 & 850 & 580 & & 192 & $22 / 6$ & $39 \pm 10$ & $41 \pm 12$ & $\leftrightarrow \mathrm{TG}$ \\
\hline $\begin{array}{l}\text { Gharekhani } \\
\text { et al [27] } \\
(2016)\end{array}$ & Iran & $\mathrm{HD}$ & 45 & 1800 & 1080 & 720 & - & 16 & $25 / 20$ & $57.2 \pm 15.19$ & $56.8 \pm 13.09$ & $\begin{array}{l}\leftrightarrow \mathrm{LDL}, \downarrow T G, \\
\downarrow T C, \downarrow H D L\end{array}$ \\
\hline $\begin{array}{l}\text { Jabbari } \\
\text { et al [28] } \\
\text { (2016) }\end{array}$ & Iran & $\mathrm{HD}$ & 117 & 3000 & & - & & 12 & $75 / 25$ & $\begin{array}{l}61.05 \pm \\
17.42\end{array}$ & $64.58 \pm 12.61$ & $\begin{array}{l}\leftrightarrow \mathrm{TC}, \leftrightarrow \mathrm{TG}, \\
\leftrightarrow \mathrm{LDL} \\
, \uparrow \mathrm{HDL}\end{array}$ \\
\hline $\begin{array}{l}\text { Khajehdehi }[29] \\
(\mathbf{2 0 0 0 )}\end{array}$ & Iran & $\mathrm{HD}$ & 30 & 1500 & & - & & 8 & $15 / 15$ & $32.4 \pm 9.2$ & $32.7 \pm 10.7$ & $\begin{array}{l}\leftrightarrow \mathrm{TC}, \\
\downarrow \mathrm{TG}, \downarrow \mathrm{LDL}, \\
\uparrow \mathrm{HDL}\end{array}$ \\
\hline $\begin{array}{l}\text { Moeinzadeh [30] } \\
\text { et al (2011) }\end{array}$ & Iran & $\mathrm{HD}$ & 52 & 3000 & 540 & 360 & - & 24 & $36 / 16$ & $\begin{array}{l}58.34 \pm \\
14.36\end{array}$ & $57.76 \pm 15.56$ & $\begin{array}{l}\uparrow H D L, \leftrightarrow L D L, \\
\leftrightarrow T C, \\
\leftrightarrow T G\end{array}$ \\
\hline $\begin{array}{l}\text { Naini et al [31] } \\
\text { (2015) }\end{array}$ & Iran & $\mathrm{PD}^{\prime}$ & 90 & 3000 & 540 & 360 & - & 8 & $51 / 39$ & $59.36 \pm 13.4$ & $57.7 \pm 16.3$ & $\begin{array}{l}\downarrow D B P{ }^{j}, \downarrow S B P{ }^{k}, \\
\leftrightarrow H D L \\
, \leftrightarrow L D L \\
\leftrightarrow T C \\
\leftrightarrow T G\end{array}$ \\
\hline $\begin{array}{l}\text { Pettersson [32] } \\
\text { et al } \\
\text { (1994) }\end{array}$ & Sweden & $\begin{array}{l}\text { IgA } \\
\text { Nephropathy }\end{array}$ & 32 & 6000 & 2800 & 1530 & - & 24 & $25 / 7$ & 42 & 39 & $\begin{array}{l}\leftrightarrow \mathrm{HDL}, \\
\leftrightarrow \mathrm{TC} \\
\text {, } \mathrm{TG}, \\
\leftrightarrow \mathrm{LDL}, \\
\leftrightarrow \mathrm{SBP}, \\
\leftrightarrow \mathrm{DBP}\end{array}$ \\
\hline $\begin{array}{l}\text { Schmitz [33] } \\
\text { et al } \\
\text { (2002) }\end{array}$ & USA & $\mathrm{HD}$ & 24 & 4000 & 1760 & 960 & - & 48 & $11 / 13$ & $54 \pm 3$ & $52 \pm 6$ & $\downarrow T G$ \\
\hline $\begin{array}{l}\text { Tayyebi- } \\
\text { Khosroshahi } \\
\text { et al [34] } \\
(2013)\end{array}$ & Iran & $\mathrm{HD}$ & 88 & 3000 & 540 & 360 & - & 8 & $63 / 25$ & 48.60 & 51.50 & $\begin{array}{l}\leftrightarrow \mathrm{HDL}, \leftrightarrow \leftrightarrow \mathrm{LDL}, \\
\leftrightarrow \mathrm{TC}, \leftrightarrow \mathrm{TG}\end{array}$ \\
\hline $\begin{array}{l}\text { Tayyebi- } \\
\text { Khosroshahi } \\
\text { et al [35] } \\
(2010)\end{array}$ & Iran & $\mathrm{HD}$ & 75 & 3000 & 540 & 360 & - & 8 & $49 / 26$ & $49.3 \pm 1.8$ & $48.8 \pm 2.7$ & $\begin{array}{l}\uparrow G P X, \downarrow M D A \\
\uparrow S O D,\end{array}$ \\
\hline
\end{tabular}

${ }^{\mathrm{a}}$ Hemodialysis, ${ }^{\mathrm{b}}$ Chronic Renal Failure, ${ }^{\mathrm{c}}$ Total cholesterol, ${ }^{\mathrm{d}}$ Triglyceride, ${ }^{\mathrm{e}}$ High-density lipoprotein, ${ }^{\mathrm{f}}$ low-density lipoprotein, ${ }^{\mathrm{g}}$ Malondialdehyde, ${ }^{\mathrm{h}}$ Glutathione peroxidase, ${ }^{\mathrm{i}}$ Superoxide dismutase, ${ }^{\mathrm{j}}$ diastolic blood pressure, ${ }^{\mathrm{k}}$ Systolic blood pressure, ' peritoneal dialysis

the effect of omega-3 FAs on HDL in CKD patients did not show significant changes (SMD: -0.12 ; 95\% CI: 0.60, 0.36; $\mathrm{I}^{2}=87.0 \%$ ) (Fig. 3c). stratification based on omega-3 FAs intake duration indicated that omega-3 FAs decreased HDL levels in more than 10 weeks of duration in CKD patients (SMD: -0.49; 95\% CI: -0.90 , - 


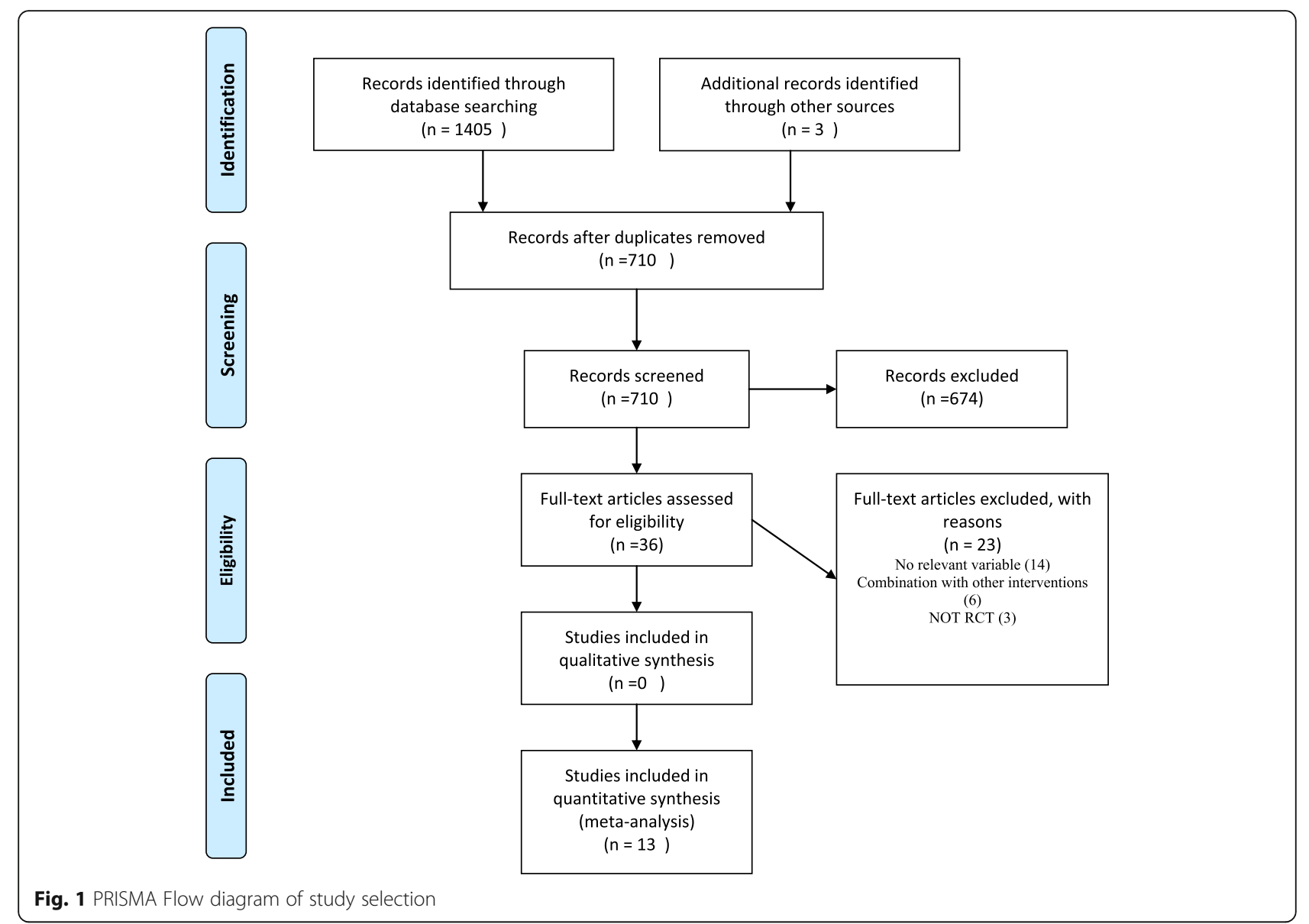

$0.09 ; \mathrm{I}^{2}=71.8 \%$ ) (Table. 2) compare to less and equal than 10 weeks (SMD: 0.83; 95\% CI: $-0.32,1.97 ; \mathrm{I}^{2}=$ 92.6\%). Subgroup analysis based on omega-3 FAs doses did not show any significant changes (Table. 2). Nine trials evaluated the effect of omega-3 FAs on LDL levels in CKD patients. Meta-analysis indicated that effect omega-3 FAs supplementation did not have significant effects on LDL levels (SMD: -0.10; 95\% CI: $-0.27,0.07$; $\mathrm{I}^{2}=00.0 \%$ ) (Fig. 3d). Subgroup analysis based on duration and dose of omega-3 FAs supplementation did not show any significant changes in this effect (Table 2).

\section{Oxidative stress}

The result of our meta-analysis indicated that omega-3 FAs supplementation significantly increase GPx (SMD: 0.50; 95\% CI: 0.14, 0.86; $\mathrm{I}^{2}=00.0 \%$ ) (Fig. 4a), and SOD activities (SMD: 0.58; 95\% CI: 0.27, 0.90; $\mathrm{I}^{2}=00.0 \%$ ) (Fig. 4b), and also significantly decrease MDA levels (SMD: -0.91; 95\% CI: $-1.29,-0.54 ; \mathrm{I}^{2}=00.0 \%$ ) (Fig. 4c) in CKD patients.

\section{Sensitivity analysis and publication bias assessment}

The main outcomes of the meta-analysis did not alter after drop out of any single of the included trials except for the condition as follow: The significant finding of the meta-analysis of the effect omega-3 FAs supplementation on TC altered to "insignificant" after drop out of the dataset of Ateya et al. [24] According to Begg and Egger test there was no publication bias in our results. Findings of the funnel plots are presented in Additional file 3.

\section{Discussion}

This systematic review and meta-analysis investigated the efficacy of omega-3 FAs supplementation on cardiometabolic outcomes and oxidative stress parameters in patients with CKD. Our results indicated that omega-3 FAs supplementation significantly reduces TC, TG, and MDA levels and substantially increases SOD and GPx activity. However, our results show that omega-3 FAs intake has no significant effects on HDL, LDL and blood pressure. Several systematic reviews evaluated the effects of omega-3 FAs intake on CKD patients. It should be noted that CKD is a very heterogeneous disease. IgA nephropathy, CKD, and HD patients are collectively referred to as CKD patients, but the significance of improving lipids, blood pressure, and oxidative stress markers differ depending on the pathology, so due to 
A

Study

$\operatorname{SMD}(95 \% \mathrm{Cl}) \quad$ Weight

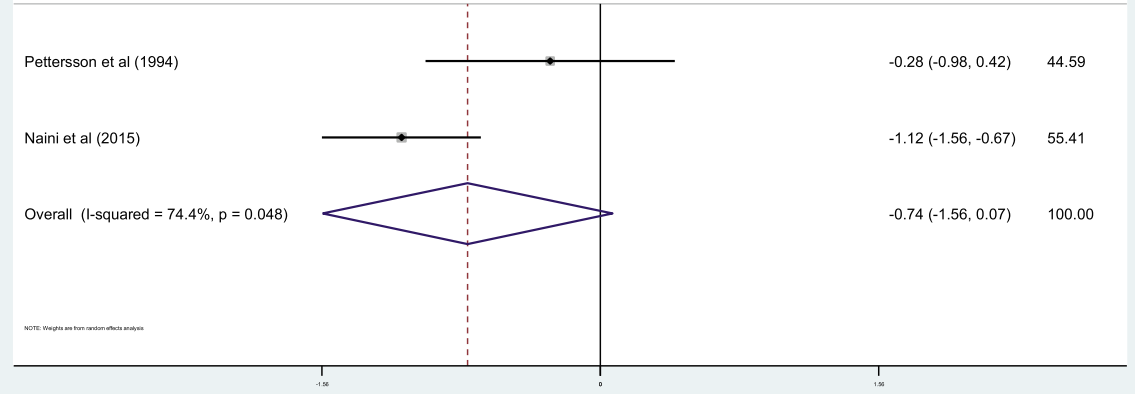

$\mathrm{B}$

Study

ID

$\operatorname{SMD}(95 \% \mathrm{Cl}) \quad$ Weight

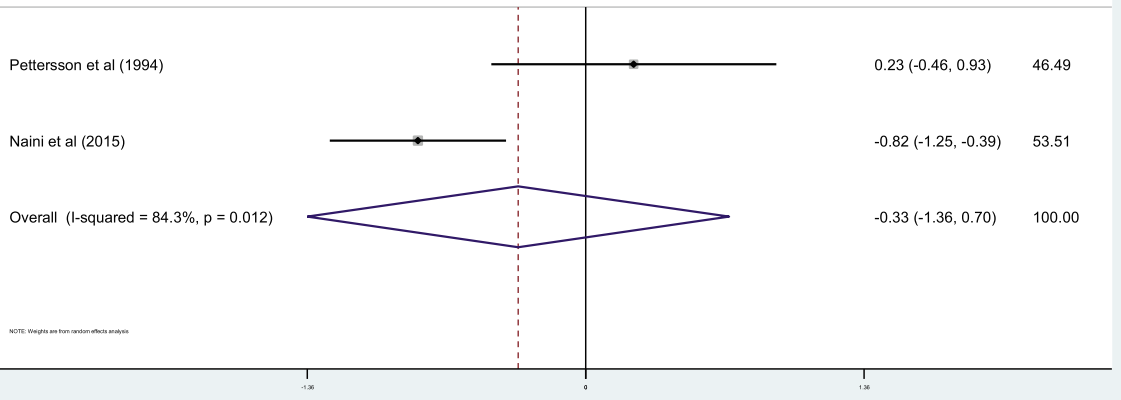

Fig. 2 Forest plot of the effect of omega-3 FAs supplementation on SBP (a) and DBP (b) in CKD patients

great heterogeneity current results should be declared with caution.

In line with our results, Saglimbene et al. in 2020 [37] demonstrated that omega-3 FAs intake might decrease cardiovascular mortality in hemodialysis patients, but it is uncertain whether omega-3 FAs intake reduces the risk of mortality or ESKD in subjects with CKD. Wu et al. [38] also indicated that omega-3 FAs supplementation might improve inflammatory factors in dialysis patients. In previous systematic reviews, omega-3 FAs intake has beneficial effects on the Lipid profile of CKD patients $[39,40]$.
Our results indicated that omega-3 FAs intake did not have a significant impact on systolic and dyastolic blood pressure in patients with CKD. However, the small number of included studies that evaluated the effect of omega-3 FAs intake on blood pressure in CKD patients makes it difficult for us to find a possible significant effect. In addition, significant reduction was observed just in Naini et al. [31] which is conducted on PD patients, so maybe this effect is related to the specific pathophysiology of PD patients. There are several studies that demonstrated the beneficial effect of omega-3 FAs supplementation on improvement of blood pressure [41, 


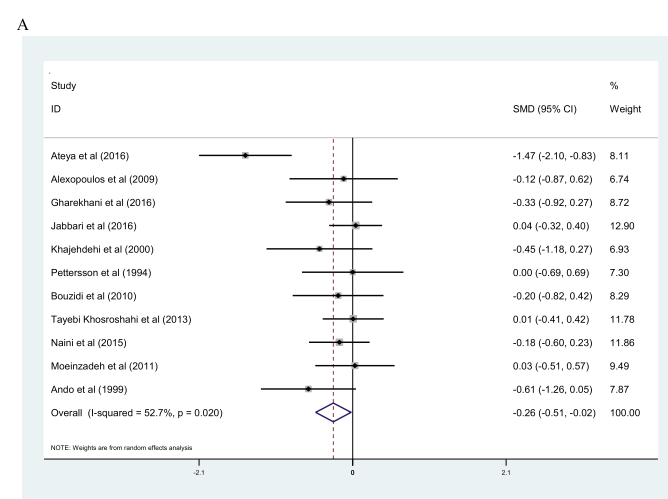

B
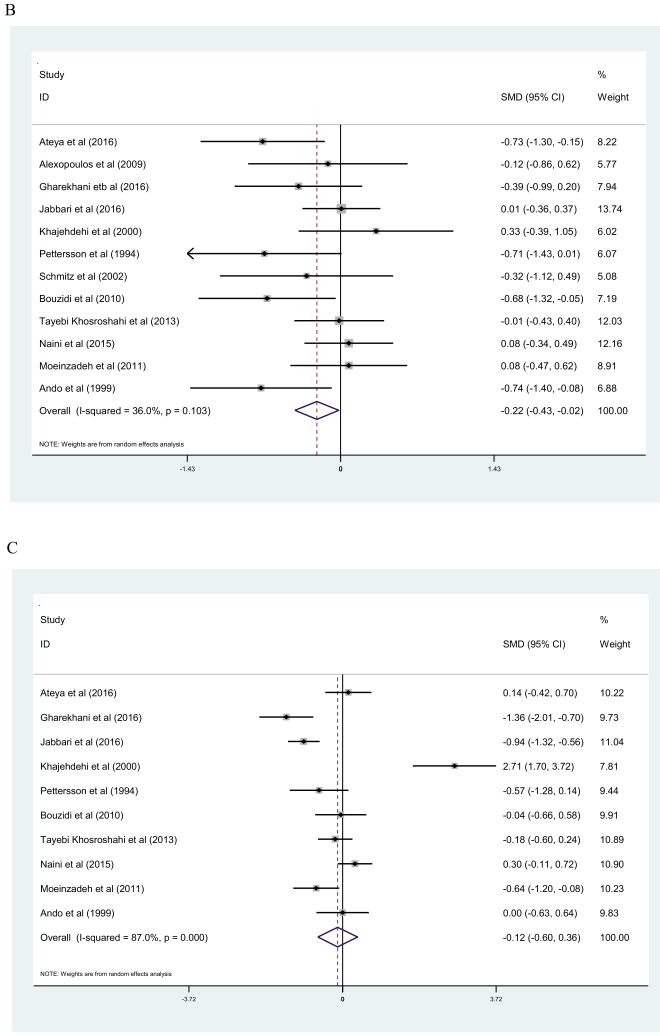

D

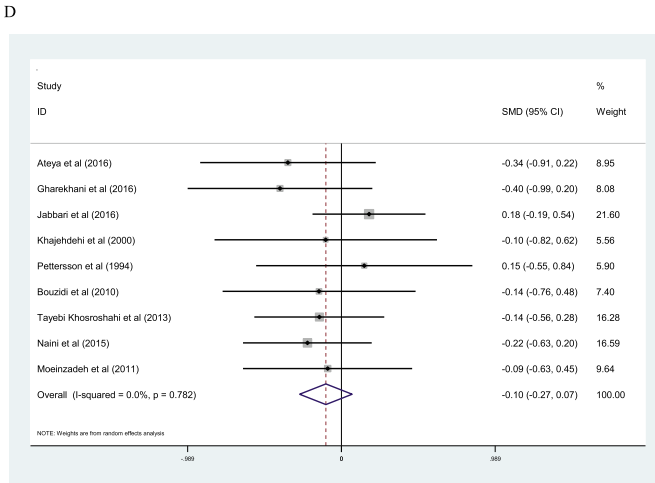

Fig. 3 Forest plot of the effect of omega-3 FAs supplementation on TC (a) TG (b), HDL (c) and LDL (d) in CKD patients
42], so maybe if there were more RCTs, we could find a significant effect of omega-3 FAs intake on blood pressure in CKD patients.

Our results indicated that omega-3 FAs intake has no effect on HDL levels in CKD patients. However, the subgroup analysis based on duration showed that omega-3 FAs intake more than ten weeks of duration significantly decrease HDL levels. This result is in contrast with Zho et al. [40] that shows that omega-3 FAs intake significantly increases HDL levels in dialysis patients. Several reasons could be proposed for these different results between present the review, and Zho et al. various included studies may cause the primary reason for these discrepancies in results. In this field, Eslick et al. [39] indicated that fish oil intake may slightly (non-significantly) increase HDL levels. Our results also showed that omega-3 FAs intake has no effect on LDL levels in CKD patients. Nevertheless, we observed a nonsignificant decrease in LDL levels, and maybe if there were more trials, we could find this reduction significant. Because previous reviews also endorse that omega-3 FAs supplementation can be useful in improving LDL levels $[43,44]$. Our meta-analysis results indicated that omega3 FAs intake significantly decreases TC levels in patients with CKD. This outcome is in accordance with Zhu et al. [40] results. Several mechanisms could be proposed for the effect of omega-3 FAs intake on TC levels. It has been shown that omega-3 FAs can reduce cholesterol levels via suppression of endogenous cholesterol synthesis [45]. Actually, it has been suggested that omega-3 FAs intake caused a significant decrease in the mRNA expression levels of 3-Hydroxy-3-Methyl-Glutaryl-Coenzyme A reductase (HMG-CoA reductase) which is the limited rate enzyme in cholesterol synthesis [46]. Recently it has been shown that cholesterol metabolism also is regulated by microRNA regulation [47]. microRNAs (miRNAs) are small non-coding RNAs that play important roles in posttranscriptional gene regulation [48, 49]. Several studies have been demonstrated that omega-3 fatty acid regulates cholesterol metabolism through modulation of different miRNAs [50]. So maybe the effect of omega-3 supplementation on cholesterol related to the regulation of miRNAs. In the present study, subgroup analysis based on omega-3 FAs dose indicated that omega-3 FAs intake less than $2000 \mathrm{mg} /$ day is more efficient to reduce TC levels compare to more than $2000 \mathrm{mg} /$ day.

Our results also indicated that omega-3 FAs intake significantly reduces TG levels. This result is following previous findings that demonstrate the beneficial effects of omega-3 FAs intake on TG levels [51-53]. Our results also show that omega-3 FAs intake reduces TG more efficiently in more than ten weeks of duration compare to less or equal to 10 weeks. Omega-3 FAs may represent 
Table 2 Subgroup analysis assessing the effect of omega-3 FAs supplementation on metabolic parameters in CKD patients

\begin{tabular}{|c|c|c|c|c|c|c|c|}
\hline Variable & Sub-grouped by & & No. of arms & effect size (SMD) & $95 \% \mathrm{Cl}$ & $I^{2}(\%)$ & P for heterogeneity \\
\hline \multirow[t]{4}{*}{ TC } & Duration & $>10$ weeks & 8 & -0.31 & $-0.66,0.03$ & 64.1 & 0.007 \\
\hline & & $\leq 10$ weeks & 3 & -0.14 & $-0.41,0.13$ & 00.0 & 0.540 \\
\hline & omega-3 FAs dosage & $\leq 2000$ mg/day & 5 & -0.61 & $-1.07,-0.14^{a}$ & 58.9 & 0.045 \\
\hline & & > 2000 mg/day & 6 & -0.04 & $-0.23,-0.15$ & 00.0 & 0.961 \\
\hline \multirow[t]{4}{*}{ TG } & Duration & $>10$ weeks & 8 & -0.36 & $-0.63,-0.10^{a}$ & 38.3 & 0.125 \\
\hline & & $\leq 10$ weeks & 3 & 0.03 & $-0.23,0.29$ & 00.0 & 0.692 \\
\hline & omega-3 FAs dosage & $\leq 2000$ mg/day & 5 & -0.36 & $-0.74,0.02$ & 40.5 & 0.151 \\
\hline & & > 2000 mg/day & 7 & -0.12 & $-0.35,0.10$ & 23.7 & 0.249 \\
\hline \multirow[t]{4}{*}{$\mathrm{HDL}$} & Duration & $>10$ weeks & 7 & -0.49 & $-0.90,-0.09^{a}$ & 71.8 & 0.002 \\
\hline & & $\leq 10$ weeks & 3 & 0.83 & $-0.32,1.97$ & 92.6 & 0.000 \\
\hline & omega-3 FAs dosage & $\leq 2000$ mg/day & 5 & 0.04 & $-0.97,1.06$ & 93.0 & 0.000 \\
\hline & & > 2000 mg/day & 5 & -0.18 & $-0.53,0.17$ & 55.2 & 0.063 \\
\hline \multirow[t]{4}{*}{ LDL } & Duration & $>10$ weeks & 6 & -0.06 & $-0.27,0.16$ & 00.0 & 0.513 \\
\hline & & $\leq 10$ weeks & 3 & -0.17 & $-0.44,0.10$ & 00.0 & 0.948 \\
\hline & omega-3 FAs dosage & $\leq 2000$ mg/day & 4 & -0.10 & $-0.40,1.20$ & 22.0 & 0.278 \\
\hline & & > 2000 mg/day & 5 & -0.13 & $-0.35,0.10$ & 00.0 & 0.937 \\
\hline
\end{tabular}

SMD Standard mean difference, Cl confidence interval. TC Total cholesterol, TG Triglyceride, HDL High density lipoprotein, LDL Low density lipoprotein ${ }^{\text {a }}$ statistically significant

their hypotriglyceridemic impacts by several possible mechanisms. It has been demonstrated that omega-3 FAs can affect the genetic or epigenetic factors and related regulatory proteins [54-57], for instance, omega-3 FAs may inhibiting hepatic lipogenesis via decreasing levels of sterol receptor element-binding protein-1c (SREBP-1c), the leading genetic switch controlling lipogenesis $[58,59]$. Omega-3 FAs have been shown to inhibit SREBP-1c transcription through a diminished trans-activating capacity of Liver $\mathrm{X}$ receptor alpha (LXR $\alpha)[60]$. Besides it has been suggested that omega-3 FAs intake upregulates fatty acids oxidation in the skeletal muscle and liver via activation of Peroxisome proliferator-activated receptor (PPARs) [61, 62], and increasing flux of glucose to glycogen via suppression of hepatocyte nuclear factor $-4 \alpha(\mathrm{HNF}-4 \alpha)$ [63, 64]. The net outcome is the change in the source of metabolic fuel from storage TG toward oxidation.

Our results show that omega-3 FAs intake improves the antioxidant defense system through increase GPx and SOD activity and decrease MDA concentrations. However the number of included studies that evaluated the effect of omega-3 FAs supplementation on oxidative stress parameters in CKD patients was very limited, so this result should be declared with caution. The antioxidant effect of omega-3 FAs supplementation in improving oxidative stress parameters has been demonstrated in previous systematic reviews [65-67]. Oxidative stress is a pivotal contributor to cardiometabolic risk factors in CKD patients [68]. Therefore, reduces cell toxicity related to increasing apoptosis and cell death through regulation of oxidative stress is very critical to cell survival [69]. Mitochondrial biogenesis is strictly related to oxidative stress and cell survival [70]. SOD activity also is related to mitochondrial biogenesis [71]. In this regard, it has been shown that omega-3 FAs intake regulates mitochondrial biogenesis through increase SOD activity [72]. In addition to the effect of omega-3 on oxidative stress, it has been shown that omega- 3 fatty acids have a strenght immunomodulatory effect which can affect antioxidant enzymes and lipid peroxidation parameters such as GPx and MDA [73]. Eicosanoids generated from arachidonic acid have critical roles in the regulation of the immune system [74]. Omega-3 fatty acids such as EPA and DHA produced different eicosanoids; these may have different functions to arachidonic acid-derived ones especially in the brain [75] and kidneys [76]. Human immune cells generally have a great amount of arachidonic acid, but arachidonic acid, DHA, and EPA amount of cells can be changed via oral intake of those fatty acids. It has been demonstrated that omega-3 FAs eicosanoids are more resistant to lipid peroxidation and decrease MDA levels [77].

\section{Strengths and limitations}

Our systematic review has evaluated the impacts of omega-3 FAs intake on CKD patients. Our database search was without language restrictions and very comprehensive. We also assessed the quality of the included trials. We investigated the impacts of different factors 
A

Study

SMD (95\% Cl) Weight

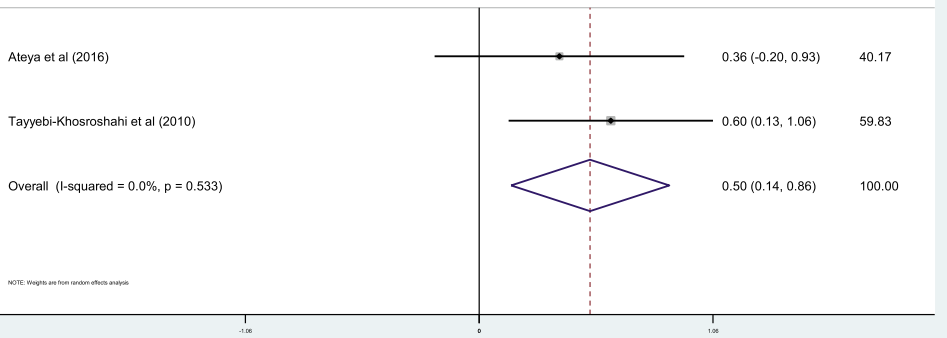

B

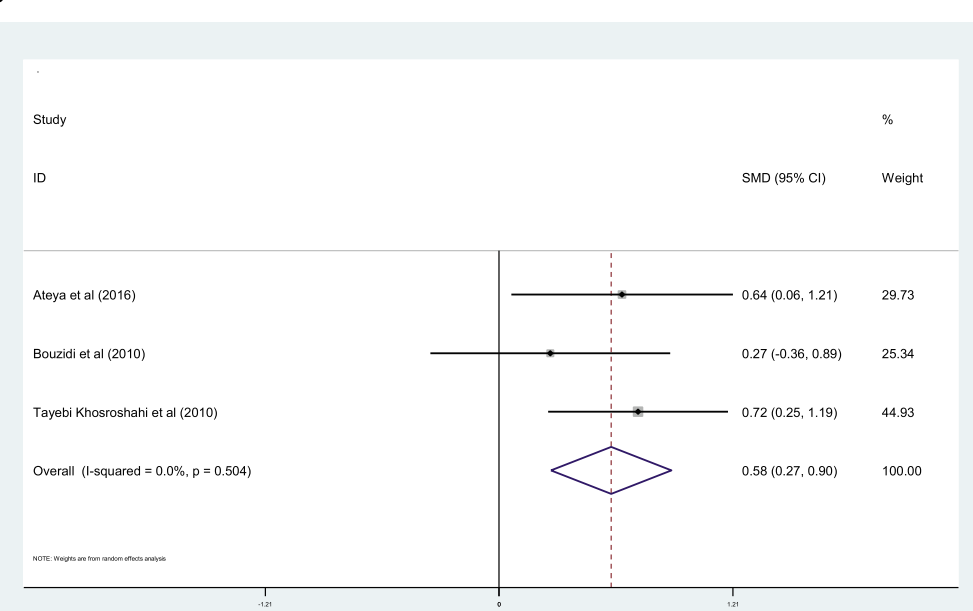

C

study

ID

$\operatorname{SMD}(95 \% \mathrm{Cl}) \quad$ Weight

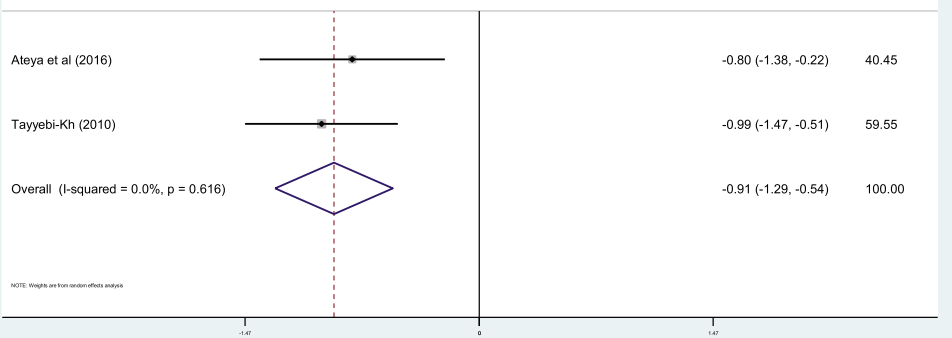

Fig. 4 Forest plot of the effect of omega-3 FAs supplementation on oxidative stress parameters; GPx(a), SOD (b) and MDA (c) 
including properties of the participants and treatment on the effects of the supplements. The included trials are very varied in the type of omega-3 FAs, dose and duration of administration. Besides, there is limited reported data about the compliance of intervention in participants. Moreover, even with contacting the authors, we could not get enough information in some of the included studies. Given the limited number of trials in each subgroup analysis, we could not conduct a metaregression analysis. In addition, the evaluation the risk of CVD disease in CKD patients in different stages may not a good way to conclude the effect of omega-3 FAs intervention on cardio-metabolic risk factors in CKD patients. It is well established that the pathogenesis of cardio-metabolic parameters is different in HD patients and non-dialysis CKD patients. Therefore, the impact of fatty acids intervention on hard outcomes is thought to vary by CKD stage and there are controversial results in the literature. For example, it has been shown that the higher the TC and TG levels are associated with, the higher the risk of developing coronary artery disease in CKD patients [78], but interventions to reduce blood lipids indicated that these treatments are effective for decrease total mortality and CVD events in early CKD stages, but have little benefit in dialysis patients [79] or even did not significantly improve CVD-related hard endpoints when limited to hemodialysis patients [80]. Moreover of thirteen included studies, ten of them were performed on HD patients so the majority of results may be related to HD patients. In addition, significant heterogeneity was encountered perhaps due to various settings, populations enrolled etc., calling for cautious interpretation of the results. Also, the effect in many variables such as blood pressure was evaluated by very few included trials and the effect may related to a specific disease condition like PD patients; thus, the evidence to support it is low. Finally, the vast majority of included trials originated from Iran; thus, extrapolation of these results to Western should be considered with caution.

\section{Conclusion}

This systematic review and meta-analysis support current evidence for a clinical benefit of omega-3 FAs intake to improve cardiometabolic parameters in CKD patients. These results show that omega-3 FAs intake significantly decrease TC, TG and MDA levels and also considerably increases SOD and GPx activity. However well-designed large randomized clinical trials still needed to provide a conclusive picture of the effect of omega- 3 FAs supplementation on oxidative stress and blood pressure parameters in patients with CKD.

\section{Abbreviations}

CKD: Chronic kidney disease; RCTs: Randomized clinical trials; LDL: Lowdensity lipoprotein; HDL: High-density lipoprotein; TG: Triglycerides; TC: Total cholesterol; MDA: Malondialdehyde; GPx: Glutathione peroxidase; SOD: Superoxide dismutase; SMD: Standard mean difference; Cl: Confidence interval; FAs: Fatty acids; DHA: Docosahexaenoic acid; EPA: Eicosapentaenoic acid; ox-LDL: oxidized low-density lipoprotein; ESRD: End-stage renal disease; MCT: Medium-chain triglyceride; TAC: Total antioxidant capacity; IQR: Interquartile range; SE: Standard Errors; SD: Standard Deviations; SBP: Systolic blood pressure; DBP: Diastolic blood pressure; HMG-CoA reductase: Hydroxy-Methyl-Glutaryl-Coenzyme A reductase; SREBP-1c: Sterol receptor element-binding protein-1c; LXRa: Liver X receptor alpha; PPARs: Peroxisome proliferator-activated receptor; HNF-4a: Hepatocyte nuclear factor $-4 a$

\section{Supplementary Information}

The online version contains supplementary material available at https://doi. org/10.1186/s12882-021-02351-9.

\section{Additional file 1.}

Additional file 2

Additional file 3.

Acknowledgements

None.

\section{Statement of ethics}

This systematic review is accordance with the World Medical Association Declaration of Helsinki.

\section{Authors' contributions}

J.H., M.M., and A.GH. equally contributed to the design of the research. S.F. and SH.A. equally contributed to analyze and interpret the data. S.F., A.H., H.H. and F.M. contributed to the conception of the research and critically revised the manuscript. A.O. and A.B.P. performed the research and collected data. All authors read and approved the final manuscript.

\section{Funding}

This study received no financial support.

Availability of data and materials

Not applicable.

\section{Declarations}

Ethics approval and consent to participate Not applicable.

Consent for publication Not applicable.

\section{Competing interests}

All authors declare no conflicts of interest.

\section{Author details}

${ }^{1}$ Clinical Research Development Unit, Ayatollah Kashani Hospital, Shahrekord University of Medical Sciences, Shahrekord, Iran. ${ }^{2}$ Department of Community Nutrition, School of Nutrition and Food Science, Isfahan University of Medical Sciences, Isfahan, Iran. ${ }^{3}$ Colorectal Research Center, Iran University of Medical Sciences, Tehran, Iran. ${ }^{4}$ Department of Education and Health

Promotion,School of Health, Iran University of Medical Sciences, Tehran, Iran.

${ }^{5}$ Cellular and Molecular Research Center, Sabzevar University of Medical

Sciences, Sabzevar, Iran. ${ }^{6}$ Department of Nutritional Science, School of Nutritional Science and Food Technology, Kermanshah University of Medical Sciences, Farabi Hospital, Faculty of Nutrition Sciences and Food Technology, Postal Code: 6715847141, Isar Square, Kermanshah, Iran. ${ }^{7}$ Pontificia

Universidad Javeriana, Bogotá, Colombia. ${ }^{8}$ Department of Nutrition, School of Public Health, Iran University of Medical Sciences, Tehran, Iran. 
Received: 3 December 2020 Accepted: 12 April 2021 Published online: 01 May 2021

\section{References}

1. Wall R, Ross RP, Fitzgerald GF, Stanton C. Fatty acids from fish: the antiinflammatory potential of long-chain omega-3 fatty acids. Nutr Rev. 2010; 68(5):280-9. https://doi.org/10.1111/j.1753-4887.2010.00287.x.

2. Khandouzi N, Shidfar F, Agah S, Hosseini AF, Dehnad A. Comparison of the effects of eicosapentaenoic acid and docosahexaenoic acid on the eradication of helicobacter pylori infection, serum inflammatory factors and total antioxidant capacity. Iranian journal of pharmaceutical research: IJPR. 2015;14(1):149-57.

3. Agah S, Shidfar F, Khandouzi N, Baghestani AR, Hosseini S. Comparison of the effects of eicosapentaenoic acid with docosahexaenoic acid on the level of serum lipoproteins in helicobacter pylori: A randomized clinical trial. Iran Red Crescent Med J. 2015;17(1):1-8

4. Delgado-Lista J, Perez-Martinez P, Lopez-Miranda J, Perez-Jimenez F. Long chain omega-3 fatty acids and cardiovascular disease: a systematic review. Br J Nutr. 2012;107(S2):S201-13. https://doi.org/10.1017/S0007114512001596.

5. Potier L, Roussel R, Zeller M, Schiele F, Puymirat E, Simon T, et al. Chronic kidney disease, diabetes, and risk of mortality after acute myocardial infarction: insight from the FAST-MI program. Diabetes Care. 2020;43(3):e434. https://doi.org/10.2337/dc19-2209.

6. Reiss AB, Miyawaki N, Moon J, Kasselman LJ, Voloshyna I, D'Avino R Jr, et al. $C K D$, arterial calcification, atherosclerosis and bone health: inter-relationships and controversies. Atherosclerosis. 2018;278:49-59. https://doi.org/10.1016/ j.atherosclerosis.2018.08.046.

7. Liu J, Tse LA, Liu Z, Rangarajan S, Hu B, Yin L, et al. Predictive values of anthropometric measurements for Cardiometabolic risk factors and cardiovascular diseases among 44048 Chinese. J Am Heart Assoc. 2019; 8(16):e010870. https://doi.org/10.1161/JAHA.118.010870.

8. Mehrkash M, Kelishadi R, Mohammadian S, Mousavinasab F, Qorbani M, Hashemi MEF, et al. Obesity and metabolic syndrome among a representative sample of Iranian adolescents. Southeast Asian J Trop Med Public Health. 2012;43(3):756.

9. Vafa M, Heshmati J, Sadeghi H, Shidfar F, Namazi N, Baradaran H, Heydarpour B, Jalili Z. Is exclusive breastfeeding and its duration related to cardio respiratory fitness in childhood? J Matern Fetal Neonatal Med. 2016 29(3):461-5.

10. Chen $L, X u X$. Effect evaluation of the long-term care insurance (LTCI) system on the health Care of the Elderly: a review. J Multidiscip Healthc. 2020;13:863-75. https://doi.org/10.2147/JMDH.S270454.

11. Neto MPC, de Souza AJ, da LdFR S, de Oliveira Silva R, de Lima Guimaraes KS, de Oliveira Y, et al. Gut microbiota and probiotics intervention: a potential therapeutic target for management of cardiometabolic disorders and chronic kidney disease? Pharmacol Res. 2018;130:152-63.

12. Rao GH. Cardiometabolic diseases: a global perspective. J Cardiol Cardiovasc Ther. 2018;12(2):555834.

13. Mofrad MD, Daneshzad E, Azadbakht L. Dietary acid load, kidney function and risk of chronic kidney disease: a systematic review and meta-analysis of observational studies. Int J Vitam Nutr Res. 2019:1-13. https://doi.org/10.1 024/0300-9831/a000584.

14. Vallejo-Vaz AJ, Robertson M, Catapano AL, Watts GF, Kastelein JJ, Packard CJ, et al. LDL-cholesterol lowering for the primary prevention of cardiovascular disease among men with primary elevations of LDL-cholesterol levels of $190 \mathrm{mg} / \mathrm{dL}$ or above: analyses from the WOSCOPS 5-year randomised trial and 20-year observational follow-up; 2017.

15. Tanaka Y, Ohya M, Yano T, Minakata T, Higashiura M, Yamamoto S, et al. Association between serum lipids, polyunsaturated fatty acids, and prognosis in maintenance hemodialysis patients. Hemodial Int. 2021;25(1): 104-12. https://doi.org/10.1111/hdi.12892.

16. Mittman N, Avram MM, Oo KK, Chattopadhyay J. Serum prealbumin predicts survival in hemodialysis and peritoneal dialysis: 10 years of prospective observation. Am J Kidney Dis. 2001;38(6):1358-64. https://doi.org/10.1053/a jkd.2001.29256.

17. Wilson AC, Mitsnefes MM. Cardiovascular disease in CKD in children: update on risk factors, risk assessment, and management. Am J Kidney Dis. 2009; 54(2):345-60. https://doi.org/10.1053/j.ajkd.2009.04.027.

18. Ateya AM, Sabri NA, El Hakim I, Shaheen SM. Effect of omega-3 fatty acids on serum lipid profile and oxidative stress in pediatric patients on regular hemodialysis: a randomized placebo-controlled study. J Ren Nutr. 2017; 27(3):169-74. https://doi.org/10.1053/j.jrn.2016.11.005.

19. Bäck M. Omega-3 fatty acids in atherosclerosis and coronary artery disease. Future science OA. 2017;3(4):FSO236. https://doi.org/10.4155/fsoa-2017-0067.

20. Foroughinia F, Foroozmehr M. Effect of pretreatment with omega-3 supplement on cardiac necrosis markers in chronic kidney disease patients undergoing elective percutaneous coronary intervention. J Res Pharm Pract. 2017;6(2):94-9. https://doi.org/10.4103/jrpp.JRPP_17_24

21. Moher D, Liberati A, Tetzlaff J, Altman DG, Group P. Preferred reporting items for systematic reviews and meta-analyses: the PRISMA statement PLoS Med. 2009;6(7):e1000097. https://doi.org/10.1371/journal.pmed.1 000097.

22. Higgins JP, Altman DG. Assessing risk of bias in included studies. Cochrane handbook for systematic reviews of interventions: Cochrane book series; 2008. p. 187-241. https://doi.org/10.1002/9780470712184.ch8.

23. Ando M, Sanaka T, Nihei $H$. Eicosapentanoic acid reduces plasma levels of remnant lipoproteins and prevents in vivo peroxidation of $L D L$ in dialysis patients. J Am Soc Nephrol. 1999;10(10):2177-84.

24. Ateya AM, Sabri NA, El Hakim I, Shaheen SM. Effect of Omega-3 fatty acids on serum lipid profile and oxidative stress in pediatric patients on regular hemodialysis: a randomized placebo-controlled study. J Renal Nutr. 2017; 27(3):169-74. https://doi.org/10.1053/j.jrn.2016.11.005.

25. Bouzidi N, Mekki K, Boukaddoum A, Dida N, Kaddous A, Bouchenak M. Effects of omega-3 polyunsaturated fatty-acid supplementation on redox status in chronic renal failure patients with dyslipidemia. J Renal Nutr. 2010; 20(5):321-8. https://doi.org/10.1053/j.jrn.2010.01.002.

26. Alexopoulos E, Stangou M, Pantzaki A, Kirmizis D, Memmos D. Treatment of severe IgA nephropathy with omega-3 fatty acids: the effect of a "very low dose" regimen. Ren Fail. 2004;26(4):453-9. https://doi.org/10.1081/JDI-20002 6763.

27. Gharekhani A, Dashti-Khavidaki S, Lessan-Pezeshki M, Khatami MR. Potential effects of Omega-3 fatty acids on insulin resistance and lipid profile in maintenance hemodialysis patients: a randomized placebo-controlled trial. Iran J Kidney Dis. 2016;10(5):310-8.

28. Jabbari M, Khoshnevis T, Jenabi A, Yousefi F. The Effect of Omega-3 Supplement on Serum Lipid Profile in Patients Undergoing Hemodialysis: A Randomized Clinical Trial. Romanian J Internal Med. 2016;54(4):222-7.

29. Khajehdehi P. Lipid-lowering effect of polyunsaturated fatty acids in hemodialysis patients. J Renal Nutr. 2000;10(4):191-5. https://doi.org/10.1 053/jren.2000.16326.

30. Moeinzadeh F, Shahidi S, Mortazavi M, Dolatkhah S, Kajbaf M, Haghjooy Javanmard S, et al. Effects of Omega-3 fatty acid supplementation on serum biomarkers, inflammatory agents, and quality of life of patients on hemodialysis. Iran J Kidney Dis. 2016;10(6):381-7.

31. Naini A, Keyvandarian N, Mortazavi M, Taheri S, Hosseini S. Effect of Omega3 fatty acids on blood pressure and serum lipids in continuous ambulatory peritoneal dialysis patients. J Res Pharm Pract. 2015;4(3):135-41. https://doi. org/10.4103/2279-042X.162356.

32. Pettersson EE, Rekola S, Berglund L, Sundqvist KG, Angelin B, Diczfalusy U, et al. Treatment of IgA nephropathy with omega-3-polyunsaturated fatty acids: a prospective, double-blind, randomized study. Clin Nephrol. 1994; 41(4):183-90.

33. Schmitz PG, McCloud LK, Reikes ST, Leonard CL, Gellens ME. Prophylaxis of hemodialysis graft thrombosis with fish oil: double-blind, randomized, prospective trial. J Am Soc Nephrol. 2002;13(1):184-90.

34. Tayebi-Khosroshahi H, Dehgan R, Habibi Asl B, Safaian A, Panahi F, Estakhri $\mathrm{R}$, et al. Effect of omega-3 supplementation on serum level of homocysteine in hemodialysis patients. Iran J Kidney Dis. 2013;7(6):479-84.

35. Tayyebi-Khosroshahi H, Houshyar J, Tabrizi A, Vatankhah AM, Zonouz NR, Dehghan-Hesari R. Effect of omega-3 fatty acid on oxidative stress in patients on hemodialysis. Iran J Kidney Dis. 2010:4(4):322-6.

36. Ioannidis JP, Trikalinos TA. The appropriateness of asymmetry tests for publication bias in meta-analyses: a large survey. Cmaj. 2007;176(8):1091-6. https://doi.org/10.1503/cmaj.060410.

37. Saglimbene VM, Wong G, van Zwieten A, Palmer SC, Ruospo M, Natale P, et al. Effects of omega-3 polyunsaturated fatty acid intake in patients with chronic kidney disease: systematic review and meta-analysis of randomized controlled trials. Clin Nutr. 2020;39(2):358-68. https://doi.org/10.1016/j.clnu.2 019.02.041.

38. Wu P-K, Yeh S-C, Li S-J, Kang Y-N. Efficacy of polyunsaturated fatty acids on inflammatory markers in patients undergoing dialysis: a systematic review 
with network meta-analysis of randomized clinical trials. Int J Mol Sci. 2019; 20(15):3645. https://doi.org/10.3390/ijms20153645.

39. Eslick GD, Howe PR, Smith C, Priest R, Bensoussan A. Benefits of fish oil supplementation in hyperlipidemia: a systematic review and meta-analysis. Int J Cardiol. 2009;136(1):4-16. https://doi.org/10.1016/j.ijcard.2008.03.092.

40. Zhu W, Dong $\mathrm{C}$, Du H, Zhang $\mathrm{H}$, Chen J, Hu X, et al. Effects of fish oil on serum lipid profile in dialysis patients: a systematic review and meta-analysis of randomized controlled trials. Lipids Health Dis. 2014;13(1):127. https://doi. org/10.1186/1476-511X-13-127.

41. Cicero AF, Derosa G, Gregori VD, Bove M, Gaddi AV, Borghi C. Omega 3 polyunsaturated fatty acids supplementation and blood pressure levels in hypertriglyceridemic patients with untreated normal-high blood pressure and with or without metabolic syndrome: a retrospective study. Clin Exp Hypertens. 2010;32(2):137-44. https://doi.org/10.3109/10641960903254448.

42. Holm T, Andreassen A, Aukrust P, Andersen K, Geiran O, Kjekshus J, et al. Omega-3 fatty acids improve blood pressure control and preserve renal function in hypertensive heart transplant recipients. Eur Heart J. 2001;22(5): 428-36. https://doi.org/10.1053/euhj.2000.2369.

43. Pirillo A, Catapano AL. Omega-3 polyunsaturated fatty acids in the treatment of atherogenic dyslipidemia. Atheroscler Suppl. 2013;14(2):237-42. https://doi.org/10.1016/S1567-5688(13)70004-7.

44. Weintraub $\mathrm{H}$. Update on marine omega-3 fatty acids: management of dyslipidemia and current omega-3 treatment options. Atherosclerosis. 2013; 230(2):381-9. https://doi.org/10.1016/j.atherosclerosis.2013.07.041.

45. Gelsomino G, Corsetto PA, Campia I, Montorfano G, Kopecka J, Castella B, et al. Omega 3 fatty acids chemosensitize multidrug resistant colon cancer cells by down-regulating cholesterol synthesis and altering detergent resistant membranes composition. Mol Cancer. 2013;12(1):137. https://doi. org/10.1186/1476-4598-12-137.

46. Kaur G, Sinclair AJ, Cameron-Smith D, Barr DP, Molero-Navajas JC, Konstantopoulos N. Docosapentaenoic acid (22: 5n-3) down-regulates the expression of genes involved in fat synthesis in liver cells. Prostaglandins Leukot Essent Fat Acids. 2011;85(3-4):155-61. https://doi.org/10.1016/j. plefa.2011.06.002.

47. Rotllan N, Fernández-Hernando C. MicroRNA regulation of cholesterol metabolism. Cholesterol. 2012;2012:1-8. https://doi.org/10.1155/2012/84784 9.

48. Jiang $Q$, Wang G, Jin S, Li Y, Wang Y. Predicting human microRNA-disease associations based on support vector machine. Int J Data Mining Bioinformatics. 2013;8(3):282-93. https://doi.org/10.1504/IJDMB.2013.056078.

49. Yin F, Xue X, Zhang C, Zhang K, Han J, Liu B, et al. Multifidelity genetic transfer: an efficient framework for production optimization. SPE J. 2021:122.

50. Corral-Jara KF, Cantini L, Poupin N, Ye T, Rigaudière JP, De Saint VS, et al. An integrated analysis of miRNA and gene expression changes in response to an obesogenic diet to explore the impact of Transgenerational supplementation with omega 3 fatty acids. Nutrients. 2020;12(12):3864. https://doi.org/10.3390/nu12123864

51. Lewis A, Lookinland S, Beckstrand RL, Tiedeman ME. Treatment of hypertriglyceridemia with omega-3 fatty acids: a systematic review. J Am Acad Nurse Pract. 2004;16(9):384-95. https://doi.org/10.1111/j.1745-7599.2 004.tb00388.x

52. Natto ZS, Yaghmoor W, Alshaeri HK, Van Dyke TE. Omega-3 fatty acids effects on inflammatory biomarkers and lipid profiles among diabetic and cardiovascular disease patients: a systematic review and meta-analysis. Sci Rep. 2019;9(1):1-10.

53. Miller PE, Van Elswyk M, Alexander DD. Long-chain omega-3 fatty acids eicosapentaenoic acid and docosahexaenoic acid and blood pressure: a meta-analysis of randomized controlled trials. Am J Hypertens. 2014;27(7): 885-96. https://doi.org/10.1093/ajh/hpu024.

54. Qu K, Wei L, Zou Q. A review of DNA-binding proteins prediction methods. Curr Bioinforma. 2019;14(3):246-54. https://doi.org/10.2174/15748936146661 81212102030

55. Zou Q, Xing P, Wei L, Liu B. Gene2vec: gene subsequence embedding for prediction of mammalian N6-methyladenosine sites from mRNA. Rna. 2019; 25(2):205-18. https://doi.org/10.1261/rna.069112.118.

56. Serini S, Ottes Vasconcelos R, Fasano E, Calviello G. Epigenetic regulation of gene expression and M2 macrophage polarization as new potential omega3 polyunsaturated fatty acid targets in colon inflammation and cancer. Expert Opin Ther Targets. 2016;20(7):843-58. https://doi.org/10.1517/1472 8222.2016.1139085.
57. Zhang J, Liu B. A review on the recent developments of sequence-based protein feature extraction methods. Curr Bioinforma. 2019;14(3):190-9. https://doi.org/10.2174/1574893614666181212102749.

58. Davidson $\mathrm{MH}$. Mechanisms for the hypotriglyceridemic effect of marine omega-3 fatty acids. Am J Cardiol. 2006;98(4):27-33. https://doi.org/10.1016/ j.amjcard.2005.12.024.

59. Reyna Gallegos S, Torres Arrunátegui G, Valenzuela R, Rincón Cervera MÁ, Villanueva Espinoza ME: Adding a purple corn extract in rats supplemented with chia oil decreases gene expression of SREBP-1C and retains $\Delta 5$ and $\Delta 6$ hepatic desaturase activity, unmodified the hepatic lipid profile. 2018, Adding a purple corn extract in rats supplemented with chia oil decreases gene expression of SREBP-1C and retains $\Delta 5$ and $\Delta 6$ hepatic desaturase activity, unmodified the hepatic lipid profile.

60. Howell lii G, Deng X, Yellaturu C, Park EA, Wilcox HG, Raghow R, et al. N-3 polyunsaturated fatty acids suppress insulin-induced SREBP-1c transcription via reduced trans-activating capacity of LXRa. Biochimica et Biophysica Acta (BBA) Mol Cell Biol Lipids. 2009:1791(12):1190-6.

61. Mori TA. Effect of fish and fish oil-derived omega-3 fatty acids on lipid oxidation. Redox Rep. 2004;9(4):193-7. https://doi.org/10.1179/13510000422 5005200 .

62. Jamilian M, Tabassi Z, Reiner Ž, Panahandeh I, Naderi F, Aghadavood E, et al. The effects of omega- 3 fatty acids from flaxseed oil on genetic and metabolic profiles in patients with gestational diabetes mellitus: a randomized, double-blind, placebo-controlled trial. Br J Nutr. 2020;123(7):126.

63. Algamas-Dimantov A, Davidovsky D, Ben-Ari J, Kang JX, Peri I, Hertz R, et al. Amelioration of diabesity-induced colorectal ontogenesis by omega-3 fatty acids in mice. J Lipid Res. 2012;53(6):1056-70. https://doi.org/10.1194/jlr. M021949.

64. Omidian M, Abdolahi M, Daneshzad E, Sedighiyan M, Aghasi M, Abdollahi H, et al. The Effects of Resveratrol on Oxidative Stress Markers: A Systematic Review and Meta-Analysis of Randomized Clinical Trials. Endocrine Metabol Immune Disorder Drug Targets. 2020;20(5):718-27.

65. Heshmati J, Morvaridzadeh M, Maroufizadeh S, Akbari A, Yavari M, Amirinejhad A, et al. Omega-3 fatty acids supplementation and oxidative stress parameters: a systematic review and meta-analysis of clinical trials. Pharmacol Res. 2019;149:104462-81.

66. Sepidarkish M, Akbari-Fakhrabadi M, Daneshzad E, Yavari M, Rezaeinejad M, Morvaridzadeh $\mathrm{M}$, et al. Effect of omega-3 fatty acid plus vitamin E cosupplementation on oxidative stress parameters: a systematic review and meta-analysis. Clin Nutr. 2020;39(4):1019-25.

67. Akbari A, Mobini GR, Agah S, Morvaridzadeh M, Omidi A, Potter E, et al. Coenzyme Q10 supplementation and oxidative stress parameters: a systematic review and meta-analysis of clinical trials. Eur J Clin Pharmacol. 2020;76:1483-99.

68. Ling XC, Kuo K-L. Oxidative stress in chronic kidney disease. Renal Replacement Therapy. 2018;4(1):1-9.

69. Wang M, Hu M, Li Z, He L, Song Y, Jia Q, et al. Construction of Tb-MOF-onFe-MOF conjugate as a novel platform for ultrasensitive detection of carbohydrate antigen 125 and living cancer cells. Biosens Bioelectron. 2019; 142:111536. https://doi.org/10.1016/j.bios.2019.111536.

70. Jiang D, Chen F-X, Zhou H, Lu Y-Y, Tan H, Yu S-J, et al. Bioenergetic crosstalk between mesenchymal stem cells and various ocular cells through the intercellular trafficking of mitochondria. Theranostics. 2020;10(16):726072. https://doi.org/10.7150/thno.46332.

71. Sebastiani M, Giordano C, Nediani C, Travaglini C, Borchi E, Zani M, et al. Induction of mitochondrial biogenesis is a maladaptive mechanism in mitochondrial cardiomyopathies. J Am Coll Cardiol. 2007;50(14):1362-9. https://doi.org/10.1016/j.jacc.2007.06.035.

72. Al-Gubory KH. Mitochondria: omega-3 in the route of mitochondrial reactive oxygen species. Int J Biochem Cell Biol. 2012;44(9):1569-73. https:// doi.org/10.1016/j.biocel.2012.06.003.

73. Calder PC. Immunomodulation by omega-3 fatty acids. Prostaglandins Leukot Essent Fat Acids. 2007;77(5-6):327-35. https://doi.org/10.1016/j. plefa.2007.10.015.

74. Jiang $Q$, Jin $S$, Jiang $Y$, Liao $M$, Feng $R$, Zhang $L$, et al. Alzheimer's disease variants with the genome-wide significance are significantly enriched in immune pathways and active in immune cells. Mol Neurobiol. 2017:54(1): 594-600. https://doi.org/10.1007/s12035-015-9670-8.

75. Zhu S, Wang X, Zheng Z, Zhao X-E, Bai Y, Liu H. Synchronous measuring of triptolide changes in rat brain and blood and its application to a 
comparative pharmacokinetic study in normal and Alzheimer's disease rats. J Pharm Biomed Anal. 2020;185:113263. https://doi.org/10.1016/j.jpba.202 0.113263 .

76. Leng S, Winter T, Aukema HM. Dietary ALA, EPA and DHA have distinct effects on oxylipin profiles in female and male rat kidney, liver and serum. J Nutr Biochem. 2018;57:228-37. https://doi.org/10.1016/j.jnutbio.2018.04.002.

77. El-Magd NFA, El-Karef A, El-Shishtawy MM, Eissa LA. Hepatoprotective effects of glycyrrhizin and omega-3 fatty acids on nuclear factor-kappa B pathway in thioacetamide-induced fibrosis in rats. Egyptian J Basic Appl Sci. 2015; 2(2):65-74. https://doi.org/10.1016/j.ejbas.2014.12.005.

78. Muntner P, He J, Astor BC, Folsom AR, Coresh J. Traditional and nontraditional risk factors predict coronary heart disease in chronic kidney disease: results from the atherosclerosis risk in communities study. J Am Soc Nephrol. 2005;16(2):529-38. https://doi.org/10.1681/ASN.2004080656.

79. Palmer SC, Craig JC, Navaneethan SD, Tonelli M, Pellegrini F, Strippoli GF. Benefits and harms of statin therapy for persons with chronic kidney disease: a systematic review and meta-analysis. Ann Intern Med. 2012;157(4): 263-75. https://doi.org/10.7326/0003-4819-157-4-201208210-00007.

80. Fellström BC, Jardine AG, Schmieder RE, Holdaas H, Bannister K, Beutler J, et al. Rosuvastatin and cardiovascular events in patients undergoing hemodialysis. N Engl J Med. 2009;360(14):1395-407. https://doi.org/10.1056/ NEJMoa0810177.

\section{Publisher's Note}

Springer Nature remains neutral with regard to jurisdictional claims in published maps and institutional affiliations.

Ready to submit your research? Choose BMC and benefit from:

- fast, convenient online submission

- thorough peer review by experienced researchers in your field

- rapid publication on acceptance

- support for research data, including large and complex data types

- gold Open Access which fosters wider collaboration and increased citations

- maximum visibility for your research: over $100 \mathrm{M}$ website views per year

At $\mathrm{BMC}$, research is always in progress.

Learn more biomedcentral.com/submissions 